\title{
Application of Latent Class Analysis in Assessing the Mental Health of Medical Students During the COVID-19 Epidemic
}

\section{Zhuang Liu}

China Medical University

\section{Yue Zhang}

China Medical University

\section{Ran Zhang}

Nanjing Brain Hospital

Rongxun Liu

Xinxiang Medical University

\section{Lijuan Liang}

The First Affiliated Hospital of Hainan Medical University

\section{Yang Wang}

Inner Mongolia Normal University

\section{Yange Wei}

Nanjing Brain Hospital

\section{Rongxin Zhu}

Nanjing Brain Hospital

Fei Wang ( $\nabla$ feiwang5656@163.com )

First Hospital of China Medical University

\section{Research Article}

Keywords: COVID-19, latent class analysis, medical students, mental health

Posted Date: February 19th, 2021

DOl: https://doi.org/10.21203/rs.3.rs-209660/v1

License: (c) (i) This work is licensed under a Creative Commons Attribution 4.0 International License. Read Full License 


\section{Title page}

\section{Application of latent class analysis in assessing the mental health of medical students during the COVID-19 Epidemic}

Zhuang Liu', Yue Zhang ${ }^{1}$, Ran Zhang ${ }^{2}$, Rongxun Liu ${ }^{2,3}$, Lijuan Liang ${ }^{4,5}$, Yang Wang ${ }^{6}$, Yange $\mathrm{Wei}^{2}$, Rongxin $\mathrm{Zhu}^{2}$, Fei Wang ${ }^{7, *}$

${ }^{1}$ School of Public health, China Medical University, Shenyang, Liaoning, China

${ }^{2}$ Department of Psychiatry, The Affiliated Brain Hospital of Nanjing Medical University, Nanjing, Jiangsu, China

${ }^{3}$ School of Medical Engineering, Xinxiang Medical University, Xinxiang, Henan, China

${ }^{4}$ Department of Psychiatry, The First Affiliated Hospital of China Medical University, Shenyang, Liaoning, China

${ }^{5}$ Department of Psychology, The First Affiliated Hospital of Hainan Medical University, Haikou, Hainan, China

${ }^{6}$ Psychology Institute, Inner Mongolia Normal University, Huhehaote, Inner Mongolia, China

${ }^{7}$ Department of Psychiatry and Radiology, The First Affiliated Hospital of China Medical University, Shenyang, Liaoning, China

*Corresponding author: Fei Wang, Department of Psychiatry and Radiology, The First Affiliated Hospital of China Medical University, 155 Nanjing North Street, Shenyang 110001, Liaoning, PR China

E-mail: feiwang5656@163.com 


\begin{abstract}
Background: The novel coronavirus disease 2019 (COVID-19) is a global public health emergency that has caused worldwide concern. The mental health of medical students under the COVID-19 epidemic has attracted much attention. This study aims to identify subgroups of medical students based on mental health status and explore the influencing factors during the COVID-19 epidemic in China.
\end{abstract}

Methods: A total of 29,663 medical students were recruited during the epidemic of COVID-19 in China. Latent class analysis of the mental health of medical students was performed using M-plus software to identify subtypes of medical students. The latent class subtypes were compared using the chi-square test. Multinomial logistic regression was used to examine associations between identified classes and related factors.

Results: In this study, three distinct subgroups were identified, namely, the high-risk group, the low-risk group and the normal group. Therefore, medical students can be divided into three latent classes, and the number of students in each class is 4325,9321 and 16,017. The multinomial logistic regression results showed that compared with the normal group, the factors influencing mental health in the high-risk group were insomnia, perceived stress, family psychiatric disorders, fear of being infected, drinking, individual psychiatric disorders, sex, educational level and knowledge of COVID-19, according to the intensity of influence from high to low.

Conclusions: Our findings suggested that latent class analysis can be used to categorize different medical students according to their mental health subgroup during the outbreak of COVID-19. The main factors influencing the high-risk group and low-risk group are basic demographic characteristics, disease history, COVID-19 related factors and behavioral lifestyle, among which insomnia and perceived stress have the greatest impact. School administrative departments could utilize more specific measures on the basis of different subgroups, and provide targeted measures.

Keywords: COVID-19; latent class analysis; medical students; mental health

\title{
Background
}

Since December 2019, a novel coronavirus pneumonia (COVID-19) outbreak has persisted in Wuhan. The World Health Organization declared that the COVID-19 outbreak constitutes a public health emergency of international concern [1]. In January 2020, the Ministry of Education issued a notice requiring colleges to appropriately postpone school opening time. For college students, extended holidays, long-term stays at home, fewer trips out of the home, and an inability to attend school and participate in social activities, may affect their academic performance and aggravate their anxiety and depression [2-4]. In a recent study, the research team identified social networking as the strongest protective factor against depression and suggested that reducing sedentary activities, such as watching TV and daytime naps, could also help reduce the risk of depression [5]. This epidemic not only led to a risk of death from infection, but 
also led to unbearable psychological pressure.

As a special group of future medical workers, medical students are an important part of the backbone of health care [6], and the healthy growth of these students can effectively promote the positive development of healthcare in the future. Compared with their normal way of living and learning, stay at home was a major contrast. In fact, the epidemic has affected mental health among those in the medical industry than among those in the general public, and they must be treated correctly to adapt to this change [7]. Mental health problems may continue into adulthood if they are not detected or properly treated. For students in clinically related disciplines, these problems can lead to many undesirable personal and professional consequences [8,9]. Therefore, it is necessary to pay attention to the mental health of medical students during the epidemic period and take targeted action to intervene with students with different characteristics.

In research on the mental health of medical students, the indirect measurement of the latent mental health can be obtained through observed and measurable behavior. Previous studies generally used the total scores of the self-assessment scales as the standard for categorizing the mental health of medical student [10,11]. The categorization standard was too simple to distinguish group characteristics. The application of latent class analysis (LCA) technology can solve this problem and provide more scientific methods for the classification of medical students' mental health during epidemic. LCA is a more scientific and rigorous statistical method to classify the potential characteristics of a population based on the score probability of each item [12]. At present, it has been widely used in sociology, psychology and disease classification or diagnosis [13,14].

Current research on COVID-19 has focused on pathogenesis, epidemiology and clinical research [15-18]. There is no latent category research on mental health during the COVID-19 epidemic. Therefore, this study intends to use the LCA method to explore the factors influencing medical students' mental health under the stress of COVID-19 pandemic to carry out targeted psychological interventions and to provide accurate decision-making references for relevant education departments.

\section{Methods}

\section{Participants}

Participants in our study came from a large cross-sectional survey conducted from March to April 2020 during the COVID-19 epidemic in China. The survey selected three medical universities, and a cluster stratified random sampling method was used. Considering the severity of the COVID-19, these data were collected through the online platform rather than face-to-face interview. All questionnaires were completed on the public account platform WeChat. Ultimately, a total of 29,663 valid questionnaires were collected. The response rate was $96.99 \%$.

The protocol of this survey was approved by the Biomedical Ethics Committee of Xinxiang Medical University and Hainan Medical University. All the participants signed online informed consent before completing the online questionnaire.

\section{Measures}

The survey consists of seven parts: basic demographic characteristics, the psychiatric 
history of individuals and family members, depression, anxiety, perceived stress, insomnia, and COVID-19 related factors. Anxiety and depression are the most common mental health problems found in Chinese medical students. In our study, mental health status was assessed by the depression and anxiety scale.

We focused on symptoms of depression, anxiety, insomnia, and stress for all students using the Chinese versions of the following measurement tools, which have good validity and reliability. The Patient Health Questionnaire-9 (PHQ-9) included 9 items and was adopted to screen for depressive symptoms in our study. Each item was scored from 0 to 3 ( 0 , not at all; 1 , several days; 2, more than half of all the days; 3 , nearly every day), with the total scores ranging from 0 to 27 . Higher scores indicated greater severity of depressive symptoms [19]. The Generalized Anxiety Disorder-7 (GAD-7) scale was a practical self-report anxiety questionnaire that comprised seven items based on seven core symptoms. The participants reported their symptoms using a 4-item rating scale ranging from 0 (not at all) to 3 (almost every day), such that the total score ranged from 0 to 21 [20]. The Insomnia Severity Index (ISI) was used to assess the severity of insomnia symptoms and comprised seven items. The participants responded to items on a 5 -item scale ranging from 0 to 4 ( 0 , not at all; 1 , mild; 2 , moderate; 3 , severe; 4, extremely severe), with the results ranging from 0 to 28 [21]. The Perceived Stress Scale (PSS) is a measure of perceived stress and has shown good reliability and validity. The participants were asked to answer each question using a 5-point rating scale ranging from 0 (never) to 4 (very often) and reported the frequency of events associated with each item in the last month. The total score ranged from 0 to 56 , with higher scores reflecting higher levels of stress [22]. The PHQ-9 and GAD-7 items were recoded into binary variables for the LCA.

\section{Statistical Analysis}

LCA models were conducted to identify data-driven subgroups using Version 8.2 of Mplus. The LCA can compensate for the deficiencies of factor analysis and structural equation model, which can only be analyzed with the continuous latent variables [23]. In LCA, classes are identified based on a set of categorical indicators, assuming that the latent categorical variable can explain the association among a set of observed variables [24]. In our study, we fitted one to six latent class models to determine the optimal number of latent classes.

The model fit indices used for the LCA included information criteria, the LoMendell-Rubin (LMR) test, the bootstrap likelihood ratio test (BLRT), and the entropy [25]. In addition, subgroup membership interpretability is another important factor in determining the optimal model. The information criteria include the Akaike information criterion (AIC), the Bayesian information criterion (BIC) and the adjusted Bayesian information criterion (aBIC). For these fit indices, the suitable model was based on the highest entropy and the lowest AIC and BIC. The entropy is an indicator of classification accuracy, with values close to 1 indicating greater accuracy [26]. Lower AIC and BIC values indicate that the model provides a better description of the data. The LMR and BLRT are significant tests that compare model fit improvement between models with $\kappa$ classes and $\kappa-1$ classes. Compared to $\kappa-1$ classes, significant $p$ values suggest a better model fit with $\kappa$ classes. 
After the appropriate number of latent classes was identified, the medical students were assigned to their most likely subgroup based on their highest posterior class probability. Chi-square tests were conducted to examine the distribution of related factors. Multinomial logistic regression was performed to estimate the correlates of related risk factors with subtypes. Statistical significance was taken as a 2-sided $p<0.05$.

\section{Results}

\section{Demographic Characteristics}

A total of 29,663 medical students were investigated this time, including 10,185 males and 19,478 females. The average age of the medical students was 21.46 years $(\mathrm{SD}=2.50)$. The demographic characteristics of medical students are shown in Table 1.

Table 1 Demographic characteristics of medical students

\begin{tabular}{ll}
\hline Characteristics & N (\%) \\
\hline Sex & \\
Male & $10,185(34.3 \%)$ \\
Female & $19,478(65.7 \%)$ \\
Education level & \\
Junior & $1968(6.6 \%)$ \\
Undergraduate & $26,909(90.7 \%)$ \\
Postgraduate & $786(2.7 \%)$ \\
Smoking & \\
Yes & $1564(5.3 \%)$ \\
No & $28,099(94.7 \%)$ \\
Drinking & \\
Yes & $4229(14.3 \%)$ \\
No & $25,434(85.7 \%)$ \\
Individual psychiatric disorders & \\
Yes & $298(1.1 \%)$ \\
No & $29,365(98.9 \%)$ \\
Family Psychiatric disorders & \\
Yes & $340(1.1 \%)$ \\
No & $29,323(98.9 \%)$ \\
\hline
\end{tabular}

\section{Model Fit Indices of LCA}

Model fit indices for various models with different latent classes are listed in Table 2. LCA with 1 to 6 classes was performed. The results showed that the AIC, BIC and aBIC decreased with increasing classification number. The model with 1 class had the largest AIC, BIC and aBIC, suggesting that this model fit the data the worst among the models. The 2-class model had the highest entropy value, but the LMR test was not significant. In the 3-class and 4-class models, the LMR and BLRT values reached significance $(\mathrm{P}<0.0001)$, but the entropy value of the 3 -class model was higher, indicating that the 3-class model fit the data better than the 4-class model did. After comprehensively considering the above indicators, we selected the 3-class model because it was parsimonious and exhibited better class separation than did the solutions 
generated by the other classifications (Table 2).

Table 2 Fitness indicators of different latent class models

\begin{tabular}{lcccccc}
\hline & AIC & BIC & aBIC & Entropy & LMR & BLRT \\
\hline 1-class & 491,182 & 491,314 & 491,264 & & & \\
2-class & 365,148 & 365,422 & 365,317 & 0.929 & 0.3274 & $<0.0001$ \\
3-class & 341,209 & 341,624 & 341,465 & 0.888 & $<0.0001$ & $<0.0001$ \\
4-class & 336,127 & 336,682 & 336,470 & 0.839 & $<0.0001$ & $<0.0001$ \\
5-class & 333,890 & 334,587 & 334,321 & 0.820 & 0.0061 & $<0.0001$ \\
6-class & 332,306 & 333,144 & 332,823 & 0.792 & $<0.0001$ & $<0.001$ \\
\hline
\end{tabular}

\section{Definition of Latent Class}

The score probability of the first class was high, which showed that the medical students in this category had poor mental health status during the epidemic period and could not be effectively adjusted, so they were labeled the 'high-risk group'. A high prevalence of insomnia and perceived stress were also featured in this subgroup. The second class was defined as the 'low-risk group' because it had a moderate score probability of depression and anxiety, which was lower than that observed in the first class and higher than that observed in the third class. Medical students of this type had a certain self-regulation ability during the epidemic. The third class had a low probability of scoring in all categories, indicating that this type of medical students had better mental health status during the epidemic and could effectively regulate their psychological condition, so it was named the normal group.

Figure 1 illustrates the profiles of mental health subtypes for the 3-class model. In Figure 1, the y-axis represents the probability of depression and anxiety symptoms, while the $\mathrm{x}$-axis shows indicator variables used for the LCA. The three lines showed symptom patterns for the three mental health subtypes. No crossing was observed among the three lines, suggesting that the modelled subtypes differed in symptom profiles. In particular, for the item regarding suicide or self-harm, a lower probability was showed across the three groups.

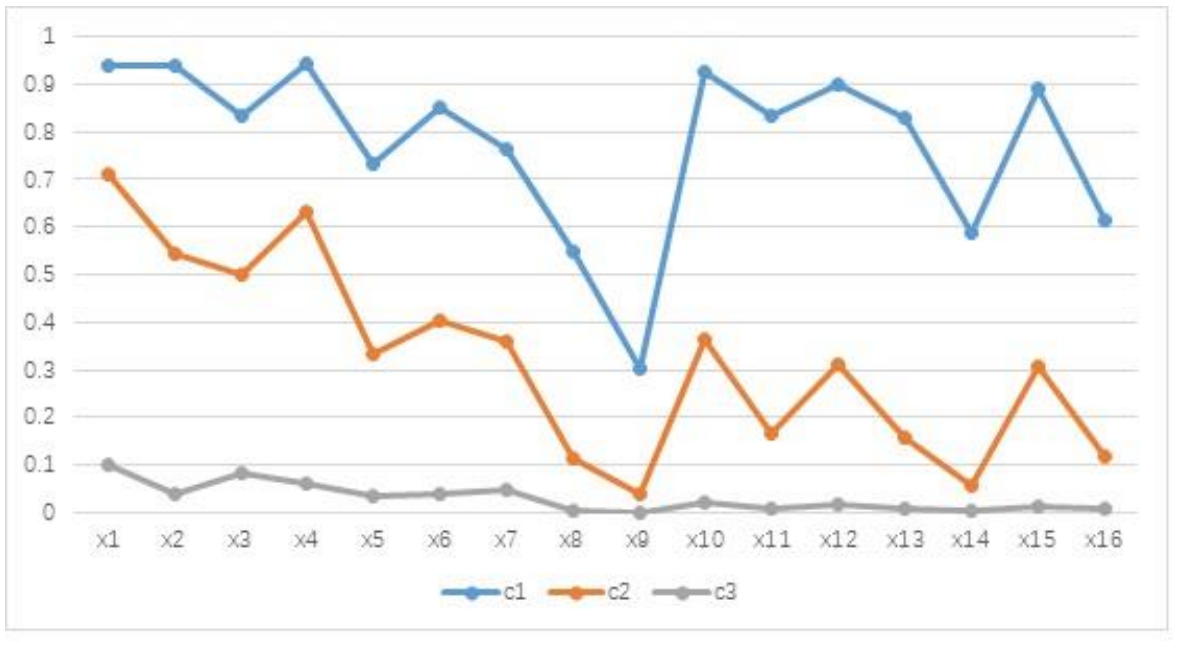

Figure 1. Profiles of latent classes of mental health 


\section{Univariate Analysis of Latent Class of Mental Health}

Gender, education level, smoking, drinking, the psychiatric disorders of the individual and family members, perceived stress, insomnia, knowledge of COVID-19, contact with confirmed or suspected patients with COVID-19, fear of being infected, and participation in mental health education on COVID-19 were significantly different across the three subtypes $(\mathrm{p}<0.05)$ (Table 3$)$. In particular, the number of medical students suffering from insomnia and perceived stress was significantly higher in the high-risk group than in the normal group.

Table 3 Univariate analysis of different latent classes of mental health status

\begin{tabular}{|c|c|c|c|c|c|}
\hline Variables & Class 1 & Class 2 & Class 3 & $\chi^{2} /$ Fisher & $\mathbf{P}$ \\
\hline Sex & & & & 70.649 & $<0.001$ \\
\hline Male & 1454 & 2908 & 5823 & & \\
\hline Female & 2871 & 6413 & 10,194 & & \\
\hline Education level & & & & 76.010 & $<0.001$ \\
\hline Junior & 335 & 499 & 1134 & & \\
\hline Undergraduate & 3817 & 8592 & 14,500 & & \\
\hline Postgraduate & 173 & 230 & 383 & & \\
\hline Smoking & & & & 169.223 & $<0.001$ \\
\hline Yes & 399 & 485 & 680 & & \\
\hline No & 3926 & 8836 & 15,337 & & \\
\hline Drinking & & & & 441.697 & $<0.001$ \\
\hline Yes & 990 & 1501 & 1738 & & \\
\hline No & 3335 & 7820 & 14,279 & & \\
\hline Individual psychiatric disorders & & & & 53.623 & $<0.001$ \\
\hline Yes & 77 & 118 & 103 & & \\
\hline No & 4248 & 9203 & 15,914 & & \\
\hline Family psychiatric disorders & & & & 168.534 & $<0.001$ \\
\hline Yes & 119 & 141 & 80 & & \\
\hline No & 4206 & 9180 & 15,937 & & \\
\hline \multicolumn{6}{|l|}{ Perceived stress } \\
\hline Yes & 3546 & 3601 & 3776 & 5013.936 & $<0.001$ \\
\hline No & 779 & 5720 & 10,923 & & \\
\hline \multicolumn{6}{|l|}{ Insomnia symptoms } \\
\hline Severe & 366 & 81 & 17 & 6573.362 & $<0.001$ \\
\hline Mild & 1516 & 980 & 194 & & \\
\hline No & 2443 & 8260 & 15,806 & & \\
\hline Knowledge of COVID-19 & & & & 632.103 & $<0.001$ \\
\hline Yes & 2624 & 6275 & 12,442 & & \\
\hline No & 1701 & 3046 & 3575 & & \\
\hline Contact suspected or confirmed & & & & 24.006 & 0.001 \\
\hline Diagnosed & 29 & 55 & 88 & & \\
\hline Suspected & 23 & 26 & 22 & & \\
\hline No & 4723 & 9240 & 15,907 & & \\
\hline
\end{tabular}




\begin{tabular}{lccccc} 
Fear of being infected & \multicolumn{3}{c}{1701.334} & $<0.001$ \\
Yes & 2287 & 3546 & 3594 & & \\
No & 2038 & 5775 & 12,423 & & $<0.001$ \\
\multicolumn{2}{l}{ Participate in mental health education on COVID-19 } & & 304.553 & \\
Yes & 2913 & 6861 & 12,714 & & \\
No & 1412 & 2460 & 3303 & & \\
\hline
\end{tabular}

\section{Multinomial Logistic Regression Analysis of Latent Classes of Mental}

\section{Health}

The category classification was used as the dependent variable, the third class (normal group) was used as the reference group, and the significant factors in univariate analysis were used as independent variables for multinomial logistic regression analysis. The results showed that compared with the normal group, medical students in the highrisk group were more likely to be female $(\mathrm{OR}=1.732, \mathrm{p}<0.001)$, have a postgraduate degree or above $(\mathrm{OR}=1.740, \mathrm{p}<0.001)$, drink $(\mathrm{OR}=2.274, \mathrm{p}<0.001)$, have individual psychiatric disorders $(\mathrm{OR}=1.898, \mathrm{p}=0.001)$, have family psychiatric disorders $(\mathrm{OR}=$ $5.030, \mathrm{p}<0.001)$, have excessive stress $(\mathrm{OR}=8.272, \mathrm{p}<0.001)$, have severe insomnia $(\mathrm{OR}=57.462, \mathrm{p}<0.001)$, have a lack of knowledge about COVID-19 (OR $=1.615, \mathrm{p}$ $<0.001)$, have a fear of being infected $(\mathrm{OR}=3.223, \mathrm{p}<0.001)$, and be unwilling to participate in mental health education on COVID-19 (OR $=1.397, \mathrm{p}<0.001)$. Meanwhile, those in the low-risk group were more likely to be female (OR $=1.534, \mathrm{p}$ $<0.001)$, have a postgraduate degree or above $(\mathrm{OR}=1.348, \mathrm{p}=0.001)$, drink $(\mathrm{OR}=$ $1.869, \mathrm{p}<0.001)$, have psychiatric disorders of the individual $(\mathrm{OR}=1.708, \mathrm{p}<0.001)$, have psychiatric disorders of the family $(\mathrm{OR}=2.861, \mathrm{p}<0.001)$, have excessive stress $(\mathrm{OR}=1.539, \mathrm{p}<0.001)$, have severe insomnia $(\mathrm{OR}=7.092, \mathrm{p}<0.001)$, have a lack of knowledge about COVID-19 (OR $=1.503, \mathrm{p}<0.001)$, have a fear of being infected $(\mathrm{OR}=1.982, \mathrm{p}<0.001)$, and be unwilling to participate in mental health education on COVID-19 $(\mathrm{OR}=1.284, \mathrm{p}<0.001)$ than were those in the normal group (Table 4). In particular, as the severity of insomnia increases, the risk of being assigned to the highrisk group increases, and the risk of medical students with severe insomnia belonging to the high-risk group was 57 times higher than that of medical students without insomnia.

Table 4 Multinomial logistic regression analysis of different latent classes of mental health status

\begin{tabular}{|c|c|c|c|c|c|c|c|c|}
\hline & \multicolumn{4}{|c|}{ High-risk group vs normal group } & \multicolumn{4}{|c|}{ Low-risk group vs normal group } \\
\hline & $\mathrm{B}$ & SE & $\mathrm{P}$ & OR $(95 \% \mathrm{CI})$ & $\mathrm{B}$ & SE & $\mathrm{P}$ & OR $(95 \% \mathrm{CI})$ \\
\hline \multicolumn{9}{|l|}{ Sex } \\
\hline Male & \multicolumn{4}{|c|}{ Ref } & \multicolumn{4}{|c|}{ Ref } \\
\hline Female & 0.549 & 0.050 & $<0.001$ & $1.732(1.570-1.910)$ & 0.428 & 0.032 & $<0.001$ & $1.534(1.440-1.635)$ \\
\hline \multicolumn{9}{|c|}{ Education level } \\
\hline Junior & \multicolumn{4}{|c|}{ Ref } & \multicolumn{4}{|c|}{ Ref } \\
\hline Undergraduate & 0.139 & 0.084 & 0.098 & $1.149(0.975-1.355)$ & 0.334 & 0.058 & $<0.001$ & $1.397(1.246-1.565)$ \\
\hline Postgraduate & 0.554 & 0.142 & $<0.001$ & $1.740(1.318-2.297)$ & 0.299 & 0.104 & 0.004 & $1.348(1.100-1.652)$ \\
\hline
\end{tabular}




\section{Smoking}

No

Yes

\begin{tabular}{llll} 
& \multicolumn{2}{c}{ Ref } \\
0.136 & 0.099 & 0.169 & $1.145(0.944-1.389)$
\end{tabular}

$\begin{array}{lll} & & \text { Ref } \\ -0.072 & 0.072 & 0.321\end{array}$

$0.931(0.808-1.07)$

Drinking

No

$$
\text { Ref }
$$

Yes

$0.822 \quad 0.067$

$<0.001 \quad 2.274(1.996-2.592)$

$\begin{array}{rrr} & \text { Ref } \\ 0.625 & 0.047 \quad<0.001\end{array}$

$1.869(1.705-2.048)$

Individual psychiatric disorders

No

Yes

$0.641 \quad 0.192$

Ref

Ref

Family psychiatric disorders

No

$0.001 \quad 1.898(1.302-2.768)$

0.535

Ref
$0.143<0.001$

$1.708(1.292-2.259)$

Yes

\section{Perceived stress}

No

$$
\begin{array}{cccc} 
& \multicolumn{2}{c}{\text { Ref }} \\
1.615 & 0.178 & <0.001 \quad 5.030(3.552-7.124)
\end{array}
$$

1.051

Ref
$0.145<0.001$

$2.861(2.153-3.804)$

Yes

Ref
$0.045<0.001 \quad 8.272(7.570-9.040)$

Insomnia symptoms

No

2.113
toms

Mild

3.499

0.431

Ref
$0.031<0.001$

$1.539(1.447-1.636)$

Ref

Severe

$\begin{array}{llll}4.051 & 0.260 & <0.001 \quad 57.462(34.518-96.658)\end{array}$

2.145

Ref

Knowledge of COVID-19

Yes

$$
\begin{array}{cccc} 
& \multicolumn{2}{c}{\text { Ref }} \\
0.479 & 0.045 \quad<0.001 \quad 1.615(1.478-1.764)
\end{array}
$$

1.959

$0.081<0.001$

$8.538(7.286-10.007)$

$0.271<0.001$

$7.092(4.171-12.059)$

No

0.407

Ref
$0.030<0.001$

$1.503(1.415-1.595)$

Contact suspected or confirmed

No

$$
\text { Ref }
$$

Suspected

$\begin{array}{ll}0.526 & 0.391\end{array}$

0.178

$1.692(0.787-3.641)$

0.576

0.861 (0.511-1.453)

Fear of being infected

No

Ref

Yes

$\begin{array}{ll}-0.149 & 0.267\end{array}$

$\begin{array}{llll}1.170 & 0.043<0.001 & 3.223(2.960-3.509)\end{array}$

$\begin{array}{lll} & & \text { Ref } \\ 0.564 & 0.309 & 0.068 \\ -0.062 & 0.181 & 0.733\end{array}$

$1.758(0.960-3.219)$

$0.940(0.660-1.340)$

\section{Participate in mental health education on COVID-19}

Yes

Ref

$\begin{array}{lllll}\text { No } & 0.334 & 0.048 & <0.001 & 1.397(1.272-1.534)\end{array}$

$0.684 \quad 0.030 \quad<0.001$

$1.982(1.870-2.100)$

Ref

\section{Discussion}

The outbreak of the COVID-19 has caused public panic and psychological pressure $[27,28]$. To prevent the escalation of the epidemic, schools have taken measures such as extending holidays to ensure that the majority of students are isolated in their current residences and complete their school-related responsibilities remotely [29]. College students must reduce the frequency of their outings, resulting in their inability to participate in social activities, which may affect their learning progress and exacerbate their anxiety and depression. Therefore, the mental health status of medical students is of great concern to medical universities [30]. In the current study, LCA was used to classify medical students' mental health during the COVID-19 epidemic. LCA is an 
important research method in the social science that assumes that individuals can be grouped into classes with similar patterns of some behaviors according to their response to a set of observed indicators [31]. Three interpretable subtypes of mental health based on LCA models were detected in the present analysis, and the entropy of the 3-class model (0.88) indicated excellent membership classification. This is consistent with previous reports involving LCA, which classified child mental health at the population level and determined the reliability of identified classes [32-34]. Meanwhile, a number of researchers have published papers encouraging the use of LCA in the classification of mental health issues because it is well suited to addressing pertinent questions [3538]. For example, Essau CA encouraged the application of LCA for studying complex multidimensional phenomena, such as mental disorders, because multiple aspects of individual functioning can be studied holistically [39]. Other researchers have suggested that LCA is an important analytic tool for studying health risk behaviors in college students [40-44]. Furthermore, it can also be used to examine the clustering of modifiable health risk behaviors and to explore the relationship between these identified clusters and mental health outcomes [45].

This study found that the mental health of medical students had obvious grouping characteristics during the COVID-19 pandemic, and the statistical indicators supported three latent classifications, namely, the 'normal group', the 'low-risk group' and the 'high-risk group'. Most medical students in this study belonged to the 'normal group', and they had low probability scores for each factor of mental health, which showed that most medical students had strong psychological adjustment ability and adaptability in isolation at home during the epidemic period. Through the probability score plot, it can be seen that all the medical students had a lower probability of scoring on the idea of dying or harming themselves. It is possible that the students were in a sensitive period of youth and had more or fewer psychological problems, but they did not have ideas of self-harm or suicide.

In the high-risk group, the probability score plot showed that the mental health problems of medical students occur in clusters rather than independently. The high-risk group had a higher probability of scoring on all other factors except $\mathrm{x} 9$, which can partly be attributed to the stressful training experience [46],such as the long length of schooling, academic pressure, and the stress of clinical practice [47]. This subtype of students may have multidimensional psychological problems, with long-term consequences on well-being and professional relationships. This is in accordance with previous studies showing that most of the students with depression symptoms were also diagnosed with generalized anxiety symptoms $[48,49]$.The cause of co-existence was related to sharing the same risk factors and symptoms [50-52].The symptoms of depression and anxiety in medical students may include slowness of thought, decreased energy, low self-worth, disturbed sleep, and difficulty concentrating, which have been known to jeopardize academic development [53,54].To prevent their behaviors from becoming extreme, these students urgently need corresponding psychological treatment measures and should be the focus of prevention and treatment. Computer-delivered cognitive behavior therapy (CCBT), which has become widely used for the growth of the internet and smartphones, can be considered $[55,56]$. 
Multinomial logistic regression analysis showed that compared with the 'normal group', there were more females in the 'high-risk group' and the 'low-risk group'. In particular, the risk of female students entering the 'high-risk group' was 1.732 times higher than that of male students, indicating that the mental health problems of female students were more prominent, which may be due to the different hormone and stressor events. Consistent with previous studies, gender differences have always existed in the mental health of medical students [57-59].In an investigation of the effects of different educational levels, it is found that the higher one's educational level is, the higher the risk of entering the 'high-risk group' and 'low-risk group'. Medical students with many years of education are more likely to have psychological problems, which may be related to the higher pressure from scientific research and work [60].Similarly, medical students with drinking habits also have a higher risk of psychological problems, which was in accordance with the findings of previous studies $[61,62]$.Compared with the normal group, medical students in the high-risk group with individual or family psychiatric disorders had a higher risk of mental health problems than did students without psychiatric disorders. A history of psychiatric disorders was consistently found to be significant correlate of depression and anxiety $[63,64]$.

This study also found significant differences in perceived stress and insomnia among medical students with different types of mental health status, and the high-risk group had more serious stress and insomnia problems. As the students spend more time in medical universities, they are faced with multiple challenges such as examination pressures, fear of failure, intense competition, lack of leisure time, exposure to patients' suffering, and scientific research pressure. Especially during the outbreak of COVID19, a long-term home life prevented medical students from coping with academia and employment, which further aggravated the pressure on the students. These factors can lead to high stress levels that negatively impact the physical, mental, and emotional health of students. High levels of stress in medical students are important predictors of anxiety and depression [65,66]. In addition, we found that insomnia might be a significant feature distinguishing the normal group from the high-risk group. A lower prevalence of insomnia was endorsed by medical students in the normal group than by those in the high-risk and low-risk groups. Insomnia has been reported to be a common residual symptom and predictor of mental health problems, which suggests that it should be taken seriously as one of the most important candidates for intervention targets in the treatment of depression and anxiety [67,68].Medical students can experience these symptoms simultaneously, with long-term consequences on wellbeing and professional relationships [69].

Apart from traditional factors, epidemic-related factors were also observed in our study. Compared with the normal group, the higher the awareness of COVID-19, the lower the risk of psychological problems for medical students in the high-risk and lowrisk groups. This phenomenon elucidated that the better understanding of preventive measures about COVID-19 for medical students, the more active they are in coping with the epidemic situation. Therefore, improving medical students' cognition of COVID-19 is beneficial to their mental health. Relevant government departments and universities should make use of social platforms, social software and other new media 
to attract medical students to consciously receive health education on epidemic prevention measures and related knowledge in COVID-19. Similarly, compared to the normal group, the risk of mental health problems in the high-risk group with fear of being infected with COVID-19 was three times higher than that in students without this fear. These results indicated that the outbreak of COVID-19 might have a significant effect on the risk of mental health issues for medical students. This was consistent with previous studies conducted in Guangzhou, which suggested that psychological consequences of the COVID-19 could be serious in college students [70]. Under the stress of the COVID-19 epidemic, the mental health status of medical students had clustering characteristics. It is urgent to implement targeted psychological interventions and health education measures according to the latent class group.

Nevertheless, the present study had several potential limitations. First, this was a cross-sectional study, thereby precluding conclusions on causality and weakening the dynamic analysis of mental health problems in medical students. Second, the instruments measuring the mental health used in our study were all conducted using self-rating scales, which may influence the accuracy of the results. Third, the medical students' mental health problems included not only depression and anxiety, but also other psychological problems that were not taken into consideration in our study. This may lead to underestimation of medical students' psychological problems.

In conclusion, this is the first study to use LCA technology to explore mental health subgroups of medical students during the COVID-19 epidemic. LCA is a useful tool for studying and classifying mental health at the population level. It was found that the mental health status of medical students had clustering characteristics. The results will be highly relevant to medical education and could be a very important reminder of the current mental health status of medical students.

\section{Acknowledgments}

We thank all participants who took part in this study. The support to recruitment by personnel in Xinxiang Medical University and Hainan Medical University is acknowledged.

\section{Author Contributions}

Fei Wang conceived and designed the study. Zhuang Liu and Yue Zhang carried out the statistical analysis and drafted the manuscript. Ran Zhang and Rongxin Zhu extracted the data and assisted with the manuscript. Yang Wang, Yange Wei, Rongxun Liu and Lijuan Liang were responsible for literature review and data collection. All authors have participated in the preparation of the manuscript and have approved the content of the submitted manuscript.

\section{Data Availability Statement}

The data that support the findings of this study are available from the corresponding author upon reasonable request.

\section{Ethics approval and consent to participate}

This study was approved by the Biomedical Ethics Committee of Xinxiang Medical University (XYLL-2020235) and Hainan Medical University (HYLL 2020005), complying with the Declaration of Helsinki. All the participants signed online informed 
consent before completing the online questionnaire.

\section{Consent for publication}

Not applicable.

\section{Competing Interests}

The authors declare that there are no conflict interests.

\section{Fundings}

Supported by National Science Fund for Distinguished Young Scholars (81725005 to Fei Wang), Liaoning Education Foundation (Pandeng Scholar to Fei Wang), Innovation Team Support Plan of Higher Education of Liaoning Province (LT2017007 to Fei Wang), Major Special Construction Plan of China Medical University (3110117059 and 3110118055 to Fei Wang).

\section{Reference}

1. Jee Y. WHO International Health Regulations Emergency Committee for the COVID-19 outbreak. Epidemiol Health. 2020;42: e2020013. doi:10.4178/epih.e2020013

2. Cao W, Fang Z, Hou G, Han M, Xu X, Dong J, et al. The psychological impact of the COVID-19 epidemic on college students in China. Psychiatry Res 2020;287:112934. doi:10.1016/j.psychres.2020.112934

3. Lima CKT, Carvalho PMM, Lima IAAS, Nunes JVAO, Saraiva JS, de Souza RI, et al. The emotional impact of Coronavirus 2019-nCoV (new Coronavirus disease). Psychiatry Res 2020; 287:112915. doi:10.1016/j.psychres.2020.112915

4. Talevi D, Socci V, Carai M, Carnaghi G, Faleri S, Trebbi E, et al. Mental health outcomes of the CoViD-19 pandemic. Riv Psichiatr 2020;55(3):137-144. doi:10.1708/3382.33569

5. Choi KW, Stein MB, Nishimi KM, Ge T, Coleman JRI, Chen CY, et al. An Exposure-Wide and Mendelian Randomization Approach to Identifying Modifiable Factors for the Prevention of Depression. Am J Psychiatry 2020;177(10): 944-954. doi:10.1176/appi.ajp.2020.19111158

6. Mullan F, Chen C, Petterson S, Kolsky G, Spagnola M. The social mission of medical education: ranking the schools. Ann Intern Med 2010;152(12):804-11. doi:10.7326/0003-4819-152-12201006150-00009

7. Duan L, Zhu G. Psychological interventions for people affected by the COVID-19 epidemic. Lancet Psychiatry 2020;7(4):300-302. doi:10.1016/S2215-0366(20)30073-0

8. Dyrbye LN, Harper W, Moutier C, Durning SJ, Power DV, Massie FS, et al. A multi-institutional study exploring the impact of positive mental health on medical students' professionalism in an era of high burnout. Acad Med 2012;87(8):1024-31. doi:10.1097/ACM.0b013e31825cfa35

9. Lins L, Carvalho FM, Menezes MS, Porto-Silva L, Damasceno H. Health-related quality of life of students from a private medical school in Brazil. Int $J$ Med Educ 2015;6:149-54. doi:0.5116/ijme.563a.5dec

10. Hope V, Henderson M. Medical student depression, anxiety and distress outside North America: a systematic review. Med Educ 2014;48(10): 963-79. doi:10.1111/medu.12512

11. Zeng W, Chen R, Wang X, Zhang Q, Deng W. Prevalence of mental health problems among medical students in China: A meta-analysis. Medicine (Baltimore) 2019;98(18):e15337. doi:10.1097/MD.0000000000015337 
12. Muthén B, Muthén LK. Integrating person-centered and variable-centered analyses: growth mixture modeling with latent trajectory classes. Alcohol Clin Exp Res 2000;24(6):882-91. doi:10.1111/j.1530-0277.2000.tb02070.x

13. Kongsted A, Nielsen AM. Latent Class Analysis in health research. J Physiother 2017;63(1): 55-58. doi:10.1016/j.jphys.2016.05.018

14. Liu Z, Zhang Y, Tian L, Sun B, Chang Q, Zhao Y. Application of latent class analysis in assessing the competency of physicians in China. BMC Med Educ 2017;17(1):208. doi:10.1186/s12909-0171039-4

15. Ahn DG, Shin HJ, Kim MH, Lee S, Kim HS, Myoung J, et al. Current Status of Epidemiology, Diagnosis, Therapeutics, and Vaccines for Novel Coronavirus Disease 2019 (COVID-19). J Microbiol Biotechnol 2020;30(3): 313-324. doi:10.4014/jmb.2003.03011

16. Ge H, Wang X, Yuan X, Xiao G, Wang C, Deng T, et al. The epidemiology and clinical information about COVID-19. Eur J Clin Microbiol Infect Dis 2020;39(6):1011-1019. doi:10.1007/s10096-02003874-Z

17. Rothan HA, Byrareddy SN. The epidemiology and pathogenesis of coronavirus disease (COVID19) outbreak. J Autoimmun 2020;109: 102433. doi:10.1016/j.jaut.2020.102433

18. Zhai P, Ding Y, Wu X, Long J, Zhong Y, Li Y. The epidemiology, diagnosis and treatment of COVID19. Int J Antimicrob Agents 2020;55(5):105955. doi:10.1016/j.ijantimicag.2020.105955

19. Du N, Yu K, Ye Y, Chen S. Validity study of Patient Health Questionnaire-9 items for Internet screening in depression among Chinese university students. Asia Pac Psychiatry 2017;9(3):10.1111. doi:10.1111/appy. 12266

20. Tong X, An D, McGonigal A, Park SP, Zhou D. Validation of the Generalized Anxiety Disorder-7 (GAD-7) among Chinese people with epilepsy. Epilepsy Res 2016;120:31-6. doi:10.1016/j.eplepsyres.2015.11.019

21. Yu DS. Insomnia Severity Index: psychometric properties with Chinese community-dwelling older people. J Adv Nurs 2010;66(10):2350-9. doi:10.1111/j.1365-2648.2010.05394.x

22. Meng R, Li J, Wang Z, Zhang D, Liu B, Luo Y, et al. The Chinese version of the Perceived Stress Questionnaire: development and validation amongst medical students and workers. Health Qual Life Outcomes 2020;18(1): 70. doi:10.1186/s12955-020-01307-1

23. Lanza ST. Latent Class Analysis for Developmental Research. Child Dev Perspect 2016;10(1): 5964. doi:10.1111/cdep.12163

24. Neuhaus V, Ring DC. Latent Class Analysis. J Hand Surg AM 2013;38(5):1018-1020. doi:10.1016/j.jhsa.2013.01.024

25. Nylund KL, Asparouhov T, Muthén BO. Deciding on the Number of Classes in Latent Class Analysis and Growth Mixture Modeling: A Monte Carlo Simulation Study. Structural Equation Modeling A Multidiplinary Journal 2007;14(4):535-569. doi:10.1080/10705510701575396

26. Celeux G, Soromenho G. An entropy criterion for assessing the number of clusters in a mixture model. Journal of Classification 1996;13:195-212. doi:10.1007/BF01246098

27. Kannan S, Shaik Syed Ali P, Sheeza A, Hemalatha K. COVID-19 (Novel Coronavirus 2019) - recent trends. Eur Rev Med Pharmacol Sci 2020;24(4):2006-2011. doi:10.26355/eurrev_202002_20378

28. Madabhavi I, Sarkar M, Kadakol N. COVID-19: a review. Monaldi Arch Chest Dis 2020;90(2): 248258. doi:10.4081/monaldi.2020.1298

29. Wang C, Pan R, Wan X, Tan Y, Xu L, Ho CS, et al. Immediate Psychological Responses and Associated Factors during the Initial Stage of the 2019 Coronavirus Disease (COVID-19) Epidemic 
among the General Population in China. Int J Environ Res Public Health 2020;17(5):1729. doi:10.3390/ijerph17051729

30. Awad F, Awad M, Mattick K, Dieppe P. Mental health in medical students: time to act. Clin Teach 2019;16(4): 312-316. doi:10.1111/tct.13047

31. Vermunt JK, Magidson J. Latent class models for classification. Computational Stats and Data Analysis 2003;41(3-4): 531-537. doi:10.1016/S0167-9473(02)00179-2

32. McElroy E, Shevlin M, Murphy J. Internalizing and externalizing disorders in childhood and adolescence: A latent transition analysis using ALSPAC data. Compr Psychiatry 2017;75:75-84. doi:10.1016/j.comppsych.2017.03.003

33. Petersen KJ, Qualter P, Humphrey N. The Application of Latent Class Analysis for Investigating Population Child Mental Health: A Systematic Review. Front Psychol 2019;10:1214. doi:10.3389/fpsyg.2019.01214

34. Rose T, Lindsey MA, Xiao Y, Finigan-Carr NM, Joe S. Mental Health and Educational Experiences Among Black Youth: A Latent Class Analysis. J Youth Adolesc 2017;46(11):2321-2340. doi:10.1007/s10964-017-0723-3

35. Au JS, Martinez de Andino A, Mekawi Y, Silverstein MW, Lamis DA. Latent class analysis of bipolar disorder symptoms and suicidal ideation and behaviors. Bipolar Disord 2020;00:1-10. doi:10.1111/bdi.12967

36. Liao L, Wu Z, Mellor D, Peng D, Zhang C, Xu J, et al. Subtypes of treatment-resistant depression determined by a latent class analysis in a Chinese clinical population. J Affect Disord 2019;249:8289. doi:10.1016/j.jad.2019.02.005

37. Podlogar MC, Rogers ML, Stanley IH, Hom MA, Chiurliza B, Joiner TE. Anxiety, depression, and the suicidal spectrum: a latent class analysis of overlapping and distinctive features. Cogn Emot 2018;32(7):1464-1477. doi:10.1080/02699931.2017.1303452

38. Rahman AF, Manatunga A, Guo Y, Peng L, Warnock M, Ressler KJ, et al. A latent class analysis of PTSD symptoms among inner city primary care patients. J Psychiatr Res 2018;98:1-8. doi:10.1016/j.jpsychires.2017.11.015

39. Essau CA, de la Torre-Luque A. Comorbidity profile of mental disorders among adolescents: A latent class analysis. Psychiatry Res 2019;278:228-234. https://doi.org/10.1016/j.psychres.2019.06.007

40. Assanangkornchai S, Li J, McNeil E, Saingam D. Clusters of alcohol and drug use and other healthrisk behaviors among Thai secondary school students: a latent class analysis. BMC Public Health 2018;18(1):1272. doi:10.1186/s12889-018-6205-Z

41. Evans-Polce R, Lanza S, Maggs J. Heterogeneity of alcohol, tobacco, and other substance use behaviors in U.S. college students: A latent class analysis. Addict Behav 2016;53:80-5. doi:10.1016/j.addbeh.2015.10.010

42. Göbel K, Scheithauer H, Bräker AB, Jonkman H, Soellner R. Substance Use Patterns Among Adolescents in Europe: A Latent Class Analysis. Subst Use Misuse 2016;51(9):1130-8. doi:10.3109/10826084.2016.1160120

43. Jeon S, Lee J, Anthony JC, Chung H. Latent Class Analysis for Multiple Discrete Latent Variables: A Study on the Association Between Violent Behavior Drug-Using Behaviors. Struct Equ Modeling 2017;24(6): 911-925. doi:10.1080/10705511.2017.1340844

44. Nelon JL, De Pedro KT, Gilreath TD, Patterson MS, Holden CB, Esquivel CH. A latent class analysis of the co-occurrence of sexual violence, substance use, and mental health in youth. Subst Use Misuse 2019;54(12):1938-1944. doi:10.1080/10826084.2019.1618337 
45. Kwan MY, Arbour-Nicitopoulos KP, Duku E, Faulkner G. Patterns of multiple health riskbehaviours in university students and their association with mental health: application of latent class analysis. Health Promot Chronic Dis Prev Can 2016;36(8):163-70. doi:10.24095/hpcdp.36.8.03

46. Bond AR, Mason HF, Lemaster CM, Shaw SE, Mullin CS, Holick EA, et al. Embodied health: the effects of a mind-body course for medical students. Med Educ Online 2013;18:1-8. doi:10.3402/meo.v18i0.20699

47. Fawzy M, Hamed SA. Prevalence of psychological stress, depression and anxiety among medical students in Egypt. Psychiatry Res 2017;255:186-194. doi:10.1016/j.psychres.2017.05.027

48. Lun KW, Chan CK, Ip PK, Ma SY, Tsai WW, Wong CS, et al. Depression and anxiety among university students in Hong Kong. Hong Kong Med J 2018;24(5):466-472. doi:10.12809/hkmj176915

49. Mao Y, Zhang N, Liu J, Zhu B, He R, Wang X. A systematic review of depression and anxiety in medical students in China. BMC Med Educ 2019;19(1): 327. doi:10.1186/s12909-019-1744-2

50. Blanco C, Rubio J, Wall M, Wang S, Jiu CJ, Kendler KS. Risk factors for anxiety disorders: common and specific effects in a national sample. Depress Anxiety 2014;31(9):756-64. doi:10.1002/da.22247

51. Bore M, Kelly B, Nair B. Potential predictors of psychological distress and well-being in medical students: a cross-sectional pilot study. Adv Med Educ Pract 2016;7:125-35. doi:10.2147/AMEP.S96802

52. Mahroon ZA, Borgan SM, Kamel C, Maddison W, Royston M, Donnellan C. Factors Associated with Depression and Anxiety Symptoms Among Medical Students in Bahrain. Acad Psychiatry 2018;42(1):31-40. doi:10.1007/s40596-017-0733-1

53. Bassols AM, Okabayashi LS, Silva AB, Carneiro BB, Feijó F, Guimarães GC, et al. First- and lastyear medical students: is there a difference in the prevalence and intensity of anxiety and depressive symptoms? Braz J Psychiatry 2014;36(3):233-40. doi:10.1590/1516-4446-2013-1183

54. Moreira de Sousa J, Moreira CA, Telles-Correia D. Anxiety, Depression and Academic Performance: A Study Amongst Portuguese Medical Students Versus Non-Medical Students. Acta Med Port 2018;31(9):454-462. doi:10.20344/amp.9996

55. Rollman BL, Herbeck Belnap B, Abebe KZ, Spring MB, Rotondi AJ, Rothenberger SD, et al. Effectiveness of Online Collaborative Care for Treating Mood and Anxiety Disorders in Primary Care: A Randomized Clinical Trial. JAMA Psychiatry 2018;75(1):56-64. doi:10.1001/jamapsychiatry.2017.3379

56. Thase ME, Wright JH, Eells TD, Barrett MS, Wisniewski SR, Balasubramani GK, et al. Improving the Efficiency of Psychotherapy for Depression: Computer-Assisted Versus Standard CBT. Am J Psychiatry. 2018;175(3):242-250. doi:10.1176/appi.ajp.2017.17010089

57. Amr M, Hady El Gilany A, El-Hawary A. Does gender predict medical students' stress in mansoura, egypt? Med Educ Online. 2008;13:12. doi:10.3885/meo.2008.Res00273

58. Brenneisen Mayer F, Souza Santos I, Silveira PS, Itaqui Lopes MH, de Souza AR, Campos EP, et al. Factors associated to depression and anxiety in medical students: a multicenter study. BMC Med Educ 2016;16(1):282. doi:10.1186/s12909-016-0791-1

59. Kunwar D, Risal A, Koirala S. Study of Depression, Anxiety and Stress among the Medical Students in two Medical Colleges of Nepal. Kathmandu Univ Med J 2016;14(53):22-26. PMID: 27892436.

60. Azad N, Shahid A, Abbas N, Shaheen A, Munir N. Anxiety And Depression In Medical Students Of A Private Medical College. J Ayub Med Coll Abbottabad 2017;29(1):123-127. PMID: 28712190. 
61. Goodin A, Elswick A, Fallin-Bennett A. Mental health disparities and high-risk alcohol use among non-heterosexual high school students. Perspect Psychiatr Care 2019;55(4):570-575. doi:10.1111/ppc.12394

62. Huang R, Ho SY, Wang MP, Lo WS, Lam TH. Reported alcohol drinking and mental health problems in Hong Kong Chinese adolescents. Drug Alcohol Depend 2016;164:47-54. doi:10.1016/j.drugalcdep.2016.04.028

63. Käkelä J, Nordström T, Haapea M, Jääskeläinen E, Miettunen J. Association between family history of mental disorders and outcome in psychotic disorders. Psychiatry Res 2018;270:616-621. doi:10.1016/j.psychres.2018.10.047

64. Torres C, Otero P, Bustamante B, Blanco V, Díaz O, Vázquez FL. Mental Health Problems and Related Factors in Ecuadorian College Students. Int J Environ Res Public Health 2017;14(5):530. doi:10.3390/ijerph14050530

65. Moutinho IL, Maddalena NC, Roland RK, Lucchetti AL, Tibiriçá SH, Ezequiel OD, et al. Depression, stress and anxiety in medical students: A cross-sectional comparison between students from different semesters. Rev Assoc Med Bras 2017; 63(1):21-28. doi:10.1590/1806-9282.63.01.21

66. Saravanan C, Wilks R. Medical students' experience of and reaction to stress: the role of depression and anxiety. Scientific World Journal 2014;2014:737382. doi:10.1155/2014/737382

67. Blake MJ, Trinder JA, Allen NB. Mechanisms underlying the association between insomnia, anxiety, and depression in adolescence: Implications for behavioral sleep interventions. Clin Psychol Rev 2018;63:25-40. doi:10.1016/j.cpr.2018.05.006

68. Gebara MA, Siripong N, DiNapoli EA, Maree RD, Germain A, Reynolds CF, et al. Effect of insomnia treatments on depression: A systematic review and meta-analysis. Depress Anxiety 2018;35(8):717-731. doi:10.1002/da.22776

69. Al-Khani AM, Sarhandi MI, Zaghloul MS, Ewid M, Saquib N. A cross-sectional survey on sleep quality, mental health, and academic performance among medical students in Saudi Arabia. BMC Res Notes 2019;12(1):665. doi:10.1186/s13104-019-4713-2

70. Wang ZH, Yang HL, Yang YQ, Liu D, Li ZH, Zhang XR, et al. Prevalence of anxiety and depression symptom, and the demands for psychological knowledge and interventions in college students during COVID-19 epidemic: A large cross-sectional study. J Affect Disord 2020;275:188-193. doi:10.1016/j.jad.2020.06.034 
Figures

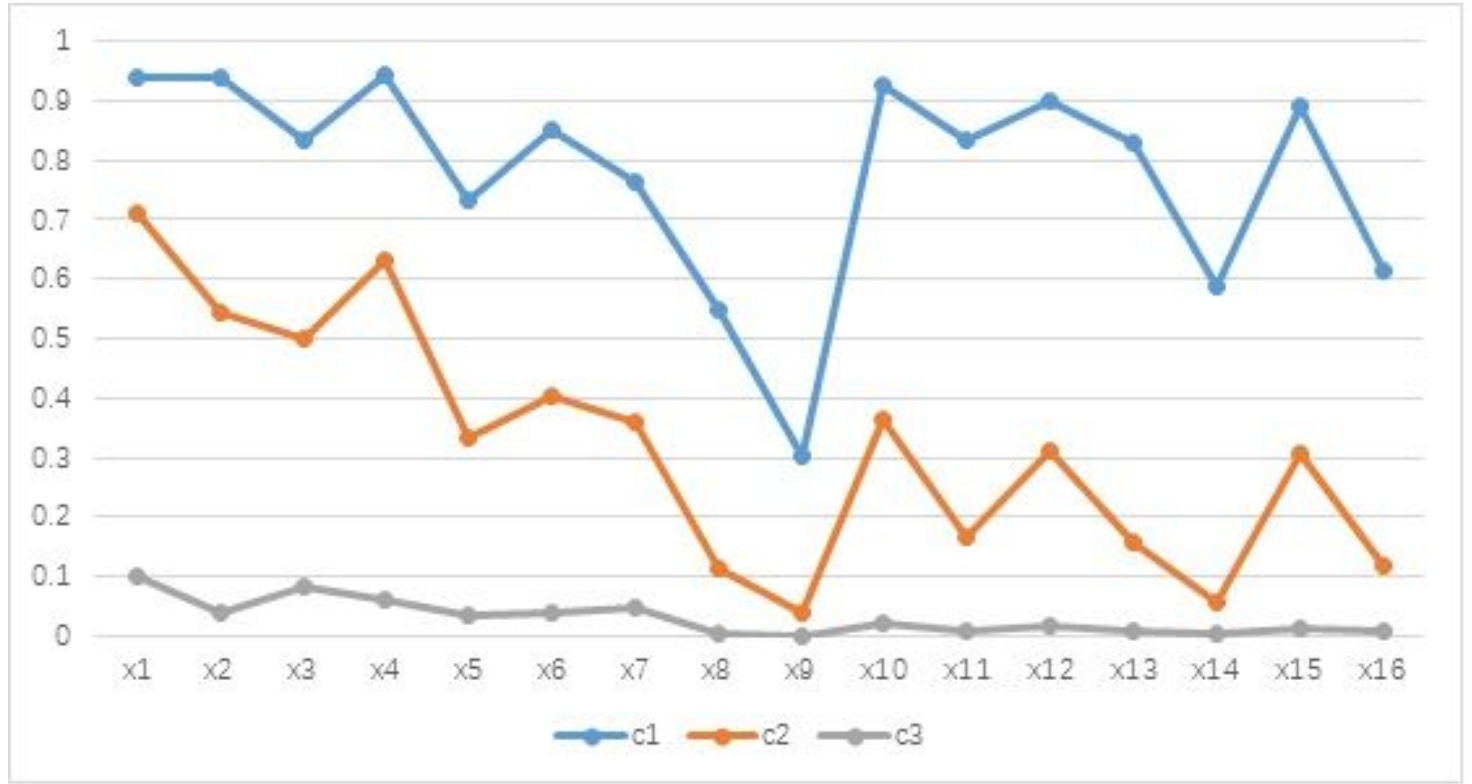

Figure 1

Profiles of latent classes of mental health 